\title{
Sistema de segmentação de imagens para quantificação de microestruturas em metais utilizando redes neurais artificiais
}

Victor Hugo Costa de Albuquerque ${ }^{1}$, Paulo César Cortez $^{2}$, Auzuir Ripardo de Alexandria ${ }^{1}$, Willys Machado Aguiar ${ }^{1}$, Edgard de Macedo Silva ${ }^{3}$

${ }^{1}$ Centro Federal de Educação Tecnológica do Ceará (CEFET CE) - Área da Indústria Avenida Treze de Maio, 2081 - Benfica, CEP 60040-531 Fortaleza - Ceará Brasil

Tel: (+55) 85 3288-3684

e-mail: victor120585@yahoo.com.br, auzuir@hotmail.com, willys@ cefetce.br

${ }^{2}$ Universidade Federal do Ceará (UFC) - Departamento de Engenharia de Teleinformática Avenida Mister Hull, S/N - Pici, CEP 60455.970 - Fortaleza - Ceará Brasil

e-mail: cortez@lesc.ufc.br

${ }^{3}$ Centro Federal de Educação Tecnológica da Paraíba (CEFET PB) - Área da Industria

Avenida $1^{\circ}$ de Maio, 720 - Jaguaribe, CEP 58015-430 - João Pessoa - Paraíba Brasil e-mail: edgard@ cefetpb.edu.br

\section{RESUMO}

O Processamento Digital de Imagens é uma área de crescente expansão em vários ramos de aplicação que utilizam a interpretação de imagens como ferramenta. A área da Metalografia Quantitativa aplicada às Ciências dos Materiais utiliza essa técnica para caracterização de frações volumétricas de fases, tamanho de grãos, determinação de distribuição de inclusões, entre outros parâmetros que influem nas propriedades dos materiais. Através de uma análise estatística preliminar, o presente trabalho tem como principal objetivo apresentar e validar o programa Segmentação Via Rede Neural Artificial (SVRNA) desenvolvido pelos autores. Este programa, baseado em redes neurais artificiais, faz a contagem percentual de constituintes em tempo reduzido em relação ao modelo convencional. O estudo é realizado, primeiramente, com a obtenção das amostras de aços ABNT 1020 e 1045 e ferro fundido nodular. A análise estatística mostra que o software é eficiente para o grau de significância admitido. Conclui-se, portanto, que o programa pode ser utilizado em aplicações na área das Ciências dos Materiais para a determinação de microestruturas.

Palavras chaves: Processo digital de imagens, metalografia quantitativa, microestruturas, redes neurais.

\section{Image segmentation system for quantification of microstructures in metals using artificial neural networks}

\section{ABSTRACT}

Digital Image Processing is an increasing expansion area in some field of application that uses the interpretation of images as tool. Quantitative Metallography area applied to Materials Sciences uses this technique for characterization of phase volumetric fractions, grain size, inclusion distribution determination and other parameters that influence the properties of the materials. The present paper has, as main objective, to present and validate the software Segmentation by Artificial Neural Network (SVRNA), developed by the authors. This software, based on artificial neural network, makes the percentile constituent counting in time reduced in relation to the conventional model. The study is carried out over ABNT 1020 and 1045 steel and nodular cast iron samples. Statistical analysis showed that this software is efficient for admitted degree of significance. It has concluded, therefore, that the program can be used in applications in the field of Material Sciences for determination of microstructures.

Keywords: Digital image processing, quantitative metallography, microconstituint, neural network. 


\section{INTRODUÇÃO}

O homem, desde os primórdios de sua existência, tem procurado construir ferramentas de modo a auxiliá-lo em sua sobrevivência neste planeta. Na época das cavernas, por exemplo, as pedras lascadas serviram para este propósito. Com sua evolução, o homem tem criado ferramentas e máquinas cada vez mais sofisticadas, ao mesmo tempo em que novas aplicações e necessidades surgem, exigindo invenções cada vez mais inteligentes.

Um dos maiores desafios existentes no desenvolvimento de máquinas é, sem dúvida, a criação de equipamentos com comportamento inteligente, ou seja, que possam resolver problemas de forma análoga ao modo que um homem os resolveriam. Assim, grandes avanços têm sido obtidos dentro da área de Inteligência Artificial, que tem como objetivo a pesquisa e desenvolvimento tecnológico para construção de máquinas com comportamento inteligente. É uma tarefa difícil, pois existem inúmeras tarefas que, para qualquer ser humano, são comuns, como a visão, audição, caminhar em duas pernas, reconhecer padrões, falar etc, mas que não são triviais para máquinas.

Dentre essas tarefas citadas, a visão tem merecido uma atenção especial, pela grande quantidade de aplicações [1, 2]. Inicialmente oriunda da Inteligência Artificial, a Visão Artificial tornou-se uma área distinta que procura construir máquinas capazes de ter algum tipo de capacidade visual, podendo ajudar ao homem a desenvolver suas tarefas diárias com rapidez e precisão. Essa nova área emprega técnicas das áreas de Inteligência Artificial, Processamento Digital de Imagens e Reconhecimento de Padrões []].

Dentre as técnicas utilizadas em Inteligência Artificial e Reconhecimento de Padrões, destacam-se as Redes Neurais Artificiais (RNA). Essas têm sido utilizadas em várias aplicações que envolvem reconhecimento de padrões pelas suas características de alto grau de paralelismo, rapidez na classificação e aprendizagem através de exemplos [4].

Redes Neurais Artificiais têm sido empregadas em vários ramos das Ciências dos Materiais, tais como: controle de soldagem, em deduções de relações entre variáveis e interações em ensaios de impacto Charpy, composição de modelos de matrizes cerâmicas, modelagem de elementos de liga, controle do processo de dopagem em semicondutores, em segmentação de imagens de microestruturas de matérias, entre outros $[\underline{5}-\underline{8}]$.

Neste trabalho é apresentado o programa SVRNA capaz de realizar a contagem de microestruturas em metais. O SVRNA é comparado com a Metalografia Convencional, aplicado em amostras de aços e ferro fundido nodular.

\section{METALOGRAFIA QUANTITATIVA CONVENCIONAL}

A Metalografia Quantitativa, aplicada às Ciências dos Materiais, é utilizada para encontrar uma relação simples entre as propriedades de um metal e a sua microestrutura que procure exprimir, em termos precisos, determinados fatores ou parâmetros estruturais. Sem tal possibilidade a apreciação desses parâmetros não pode ser senão qualitativa e, conseqüentemente, de interesse limitado. Neste contexto, a metalografia quantitativa fornece meios de quantificar a microestrutura, cujo objetivo é determinar a quantidade, a forma, o tamanho e a distribuição dos constituintes, fases e defeitos.

As medidas de Metalografia Quantitativa são em superfícies opacas e destas medidas devem ser obtidas relações que caracterizem tridimensionalmente a microestrutura. Muitos dos parâmetros em terceira dimensão podem ser obtidos de maneira exata, por meio de medidas em duas dimensões, mas estas relações exatas não são disponíveis em todos os casos. Algumas vezes, a Metalografia Quantitativa utiliza parâmetros que não representam os valores reais em terceira dimensão, mas que caracterizam a microestrutura.

A Metalografia Quantitativa tem utilização na avaliação de parâmetros estruturais não só para interpretação de mecanismos nos fenômenos metalúrgicos, mas também nas determinações de rotina para controle de qualidade ou estudo de suas imagens.

Por outro lado, há determinações especiais que só esporadicamente são efetuadas quando necessárias em pesquisas específicas, como a orientação de cristais ou a análise de linhas de escorregamento ou, ainda, relações angulares [11].

A classificação e quantificação de microestruturas são importantes para o estudo e caracterização de metais, bem como para a otimização do processo de fabricação dos mesmos. Esta classificação e quantificação que, em geral, são realizadas de forma manual utilizando um disco reticulado com 25 interseções, são processos lentos e enfadonhos e, dada estas características, não trazem bons resultados, visto que o especialista acaba cometendo erros nas leituras.

Para solucionar este problema, são desenvolvidos sistemas de Visão Artificial que apresentam grandes vantagens em relação ao método tradicional manual. Estas vantagens são os aumentos na precisão das leituras e maior independência do operador. Porém, as dificuldades na preparação das amostras dos metais ou na aquisição das imagens, como distorções na parte óptica ou irregularidades na iluminação, 
podem produzir não uniformidade na tonalidade das microestruturas, dificultando sua quantificação e seu reconhecimento, inclusive para o processo tradicional.

Existem medidas básicas que a Metalografia Quantitativa Convencional utiliza para determinar as porções de microestruturas que compõem um determinado metal.

\subsection{Medidas Básicas}

As principais medidas básicas, utilizadas neste trabalho, que podem ser efetuadas em secções planas, seguidas com suas simbologias e definições são apresentadas nesta subseção.

\subsubsection{Fração Pontual}

A fração pontual $P p$ é definida pela razão entre o número de pontos incidentes $P c$ no objeto de interesse, pelo número total de pontos de uma determinada grade $P$, sendo expressa por:

$$
P p=\frac{P c}{P}
$$

A fração pontual é uma das técnicas mais simples e mais generalizadas da Microscopia Quantitativa, particularmente, devido às relações de equivalência com a fração volumétrica [10]. A análise pontual ou contagem por pontos corresponde à percentagem de pontos que caem no interior da microestrutura em estudo na seção polida, em relação ao número total de pontos de ensaio $P$.

A contagem por pontos desenvolveu-se depois dos métodos que utilizam áreas e linhas, e é Thompson quem, em 1930, aplica-a pela primeira vez à análise de microestruturas, utilizando uma ocular especial ou a projeção simultânea de uma rede e de um diapositivo da estrutura. Em 1934, Glagolev introduz a contagem unidimensional, em que o provete (tubo de ensaio) se desloca sob o cruzamento do retículo da ocular. Neste método, podem aplicar-se pontos de ensaio casuais ou pontos com uma distribuição regular, por exemplo, nos nós de um reticulado de malha quadrada. A contagem por pontos diz-se casual no primeiro caso e sistemática no segundo, sendo a precisão desta superior à primeira [14].

No caso da contagem casual pode-se utilizar como ponto de ensaio o cruzamento do retículo de um ocular segundo o método de Glagolev, isto é, movimentando o provete em quantidades discretas e aleatórias e anotando cada vez que o ponto de ensaio cai na configuração a quantificar.

A contagem sistemática pode subdividir-se em bidimensional e unidimensional, subordinadas a uma dada área ou a uma linha.

\subsubsection{Fração Volumétrica}

A fração volumétrica $V v$ é definida pela razão entre o volume dos objetos (da fase) $V f$ e a unidade de volume-teste $V$ (ensaio), cuja expressão é dada por

$$
V v=\frac{V f}{V}
$$

A determinação da proporção de um constituinte ou fase por unidade de volume é um método moroso e extremamente fastidioso, pois, implica em medidas de áreas em secções sucessivas, obtidas por planos paralelos no(s) provete(s) aleatoriamente escolhidos, de modo a se obter $V$.

Delesse (1848) e Risiwal (1903) demonstraram a equivalência da fração volumétrica $V v$ e e da fração pontual $P p$ desde que a distribuição da fase ou constituinte seja casual e suas medidas efetuadas aleatoriamente numa seção polida representativa. Deste modo, simplifica-se e reduz aquela determinação de medidas, tornando-a simples e direta. Estudos comparativos do erro relativo para os dois métodos feitos por Hilliard, levam à preferência pela análise pontual por contagem sistemática de pontos. Assim, a relação básica que se utiliza para a determinação da fração volumétrica é $V v=P p[11]$.

Além de medidas básicas, a Metalografia Quantitativa Convencional necessita de medidas estatísticas, descritas a seguir.

\subsection{Medidas Estatísticas}

As principais medidas estatísticas empregadas são o desvio padrão $\sigma(x)$, desvio padrão em relação à média $\sigma(\bar{x})$, limites de confiança $L C$, resultado do valor da fração volumétrica e do erro relativo $E R$, este estimado em até $5 \%$. As equações usadas para obter estes parâmetros são: 


$$
\begin{aligned}
& \sigma(x)=\frac{\sqrt{\sum i\left(\Delta P g_{i}\right)^{2}}}{n-1} \\
& \sigma(\bar{x})=\frac{\sigma(x)}{\sqrt{n}} \\
& L C=\bar{x} \pm 2 \sigma(\bar{x}) \\
& E R=\frac{\sigma(\bar{x})}{\bar{x}}
\end{aligned}
$$

\subsection{Metodologia Experimental}

Para a Metalografia Quantitativa Convencional, a metodologia experimental empregada consiste na contagem dos constituintes das amostras dos aços ABNT 1020 e 1045, e ferro fundido nodular utilizando-se a contagem casual, e um disco de vidro reticulado de diâmetro $16,9 \mathrm{~mm}$, espessura de $15 \mathrm{~mm}$ e espessura dos traços $<5 \mu \mathrm{m}$. Procede-se na determinação dos parâmetros estatísticos definidos na seção anterior para cada uma das três amostras, obtendo-se os resultados a seguir.

\subsubsection{Para o aço ABNT 1020}

Para obter-se o erro relativo menor ou igual a $5 \%$ são tomados 150 pontos por campo e divididos por 25, que é o número total de pontos de ensaio, ou seja, o valor total dos nós no disco reticulado. Em seguida é calculada a fração por pontos $P p$, que é igual à fração volumétrica $V v$, cujos resultados estão mostrados na Tabela 1.

Por fim, são calculados o desvio padrão, o desvio padrão em relação à média, os limites de confiança e o erro relativo, cujos resultados são mostrados na Tabela 2.

\subsubsection{Para o aço ABNT 1045}

Com o intuito de obter-se o erro relativo menor ou igual a $5 \%$ são tomados 155 pontos por campo e divididos por 25, que é o número total de pontos de ensaio, ou seja, o valor total dos nós no disco reticulado. Em seguida é calculada a fração por pontos $P p$, que é igual à fração volumétrica $V v$, mostrados na Tabela 1 . São calculados o desvio padrão, o desvio padrão em relação à média, os limites de confiança e o erro relativo, cujos resultados são mostrados na Tabela 2.

\subsubsection{Para o Ferro Fundido Nodular}

Para obter-se o erro relativo menor ou igual a 5\% são tomados 206 pontos por campo e divididos por 25, que é o número total de pontos de ensaio, ou seja, o valor total dos nós no disco reticulado. Em seguida é calculada a fração por pontos $P p$, que é igual à fração volumétrica $V v$, mostrados na Tabela 1 . São calculados também os mesmos parâmetros estatísticos das amostras anteriores, produzindo os resultados mostrados na Tabela 2.

Tabela 1: Resultados obtidos pelo método convencional para as três amostras usadas nos testes.

\begin{tabular}{|l|c|c|c|}
\hline \multirow{2}{*}{ Tipo de Microestrutura (\%) } & \multicolumn{3}{|c|}{ Tipo de Amostra } \\
\cline { 2 - 4 } & aço ABNT 1020 & aço ABNT 1045 & Ferro Fundido Nodular \\
\hline Grafita & - & - & $24,13 \%$ \\
\hline Ferrita & $69,38 \%$ & $46,59 \%$ & $75,87 \%$ \\
\hline Perlita & $30,62 \%$ & $53,41 \%$ & - \\
\hline
\end{tabular}


Tabela 2: Medidas de parâmetros estatísticos das três amostras usadas nos testes e seus resultados.

\begin{tabular}{|l|c|c|c|}
\hline \multirow{2}{*}{ Parâmetro medido (\%) } & \multicolumn{3}{|c|}{ Tipo de Amostra } \\
\cline { 2 - 4 } & aço ABNT 1020 & aço ABNT 1045 & Ferro Fundido Nodular \\
\hline Desvio padrão - $\sigma(x)$ & 11,21 & 10,97 & 13,19 \\
\hline Desvio padrão em relação a média $-\sigma(\bar{x})$ & 0,91 & 0,88 & 0,91 \\
\hline Limite de confiança - $L C$ & 71,20 e 67,56 & 54,64 e 51,40 & 25,97 e 22,29 \\
\hline Erro médio - $E R$ & 1,32 & 1,65 & 3,81 \\
\hline
\end{tabular}

\section{METALOGRAFIA QUANTITATIVA UTILIZANDO O SVRNA}

O sistema SVRNA tem por objetivo realizar tarefas da metalografia quantitativa, mas empregando técnicas de processamento digital de imagens e inteligência artificial, especificamente Redes Neurais Artificiais (RNA). Estas são sistemas que modelam o sistema nervoso biológico de modo que se obtenham soluções para problemas computacionais complexos. Modelando os sistemas básicos do cérebro, poder-se obter uma solução de problemas intrinsecamente paralelos, não mais seriais. Problemas como os relacionados à visão computacional, controle, e vários outros problemas de Inteligência Artificial podem, então serem resolvidos com rapidez e alta confiabilidade $[\underline{12}, \underline{13}]$.

Como o sistema nervoso, as RNA não possuem componentes funcionais discretos. Existem, porém, regiões responsáveis por determinada tarefa, um alto grau de redundância e paralelismo, o que torna os sistemas implementados com esta técnica rápidos e robustos.

A característica mais importante do cérebro humano é sua capacidade de aprender. Analogamente, um dos aspectos mais importantes das RNA é que estas podem "aprender" padrões através de exemplos e os reconhecer após este aprendizado. Isto não acontece com sistemas computacionais tradicionais.

As RNAs são constituídas por um conjunto de perceptron ou neurônio artificial, sendo este um modelo de uma célula nervosa (neurônio). É a forma mais básica, ou seja, a unidade menor de uma rede neural. Redes perceptron são redes neurais de camada única e que reconhecem padrões linearmente separáveis, em geral, são problemas simples.

$\mathrm{Na}$ solução de problemas complexos são empregadas as Redes de múltiplas camadas, cujos padrões, em geral não são separáveis linearmente. Estas redes consistem de uma camada de entrada, camadas intermediárias (camadas escondidas) e uma camada de saída. Estas redes possuem duas fases distintas: treinamento e execução. O algoritmo largamente utilizado para este fim é o backpropagation e seus variantes. A regra de aprendizado é um pouco mais complexa de que a regra do perceptron simples. Este aprendizado é conhecido como "supervisionado", pois, é necessário conhecer o padrão correto para que o treinamento seja realizado, necessitando de um operador $[14,4]$.

O processo de classificação de microestruturas, utilizado pelo SVRNA, emprega uma RNA para a tarefa mais importante de um sistema de visão artificial, denominado segmentação.

\subsection{Segmentação de Imagens}

A segmentação de imagens é um dos principais processos constituintes de um sistema de Visão Artificial. Seu objetivo é separar as regiões que compõem uma imagem para que seja possível a extração de atributos (características) desta imagem. Regiões espacialmente diferentes, em uma mesma imagem, são caracterizadas como áreas com nível de cinza semelhante, ou mesma textura, ou outra característica em comum. Portanto, a segmentação consiste em atribuir um rótulo a cada pixel da imagem, identificando-o a qual região ele pertence, de acordo com suas características comuns [3].

Técnicas de segmentação, como limiar e crescimento de regiões, não se comportam bem na solução do problema de segmentação de imagens de microestruturas, dada a dificuldade de achar o limiar adequado ou as sementes adequadas para o correto crescimento das regiões. É necessária a aplicação de filtros no préprocessamento da imagem em análise, embora nem sempre esta metodologia resolva. Para amostras diferentes do mesmo material, é utilizada uma adaptação dos filtros ou a escolha de outros, em função de diferenças na aquisição da imagem ou na preparação da amostra, como ataque químico e polimento. Com base nestes problemas de segmentação utilizando-se algoritmos tradicionais de processamento digital de imagens, surge a necessidade do emprego de um método mais eficiente nesta aplicação que são as RNA. 


\subsection{Aplicação de Redes Neurais em Segmentação de Imagens}

Várias características das Redes Neurais possibilitam a sua utilização em segmentação de objetos em imagens, utilizando-se como entrada o nível de cinza ou componentes R, G e B. Uma destas características é o aprendizado através de exemplos, o que facilita a interface do sistema para um usuário leigo no que se referem as técnicas de processamento de imagens [15]. Uma outra vantagem é a rapidez na execução e a possibilidade de implementação em hardware, bem como a capacidade na classificação de padrões não linearmente separáveis também é uma outra característica importante [16].

$\mathrm{Na}$ abordagem adotada, a Rede Neural deve ser executada para cada pixel, da imagem sob análise, de forma a rotulá-los na mesma. Para tornar mais ágil a segmentação, pode-se fazer uso de várias subredes com treinamento idêntico com o intuito de executar em paralelo a segmentação da imagem, aproveitando a vantagem de arquiteturas paralelas de implementação de Redes Neurais, como implementação em hardware [17]. Isto traz uma diminuição no tempo da segmentação.

Quanto à quantidade de saídas da Rede Neural, esta pode possuir $n$ saídas, em que $n$ é o número possível de regiões que se pretende treinar a rede para a identificação e o resultado pode ser utilizado para especificar um rótulo em cada pixel, expressando a região a que ele pertence. A quantidade de neurônios presente na rede deve ser projetada de forma que seja possível que o treinamento ocupe o mínimo de memória para armazenamento dos pesos.

\subsection{O sistema SVRNA}

O SVRNA é implementado no ambiente C++ Builder 5 da Borland, em plataforma Windows 98 e utiliza uma Rede Neural aplicada em segmentação. Neste sistema, uma Rede Neural com 42 neurônios distribuídos em três camadas é utilizada. A distribuição dos neurônios ao longo das amadas (topologia) corresponde a: 3 entradas, 30 neurônios na camada intermediária e 9 neurônios na camada de saída. As entradas da Rede Neural são as componentes R, G e B de cada um dos pixels selecionados. A saída da rede, por sua vez, é a indicação de qual região, ou seja, qual pseudocor deve ser atribuída ao pixel sob análise.

A Rede Neural é utilizada no sistema para a segmentação, a classificação e a quantificação de microestruturas de metais, a partir da cor destas microestruturas. O treinamento é feito tomando uma pequena amostra dos pixels de cada microestrutura, atrelando-os a uma pseudocor que é utilizada como rótulo. Os conjuntos componentes $\mathrm{R}, \mathrm{G}$, e $\mathrm{B}$ e o número da pseudocor (codificada de 0 a 8 ) para vários pixels é utilizado como conjunto de treinamento da rede neural.

O sistema interage com usuário para coletar os pixels do conjunto de exemplos selecionados, utilizando-se o mouse, e na mesma interface se dá o treinamento da rede e sua classificação. Depois de treinada, a rede pode ser utilizada para a classificação e quantificação de imagens semelhantes, ou seja, relativas ao mesmo material no qual é submetido ao mesmo tratamento químico.

O sistema SVRNA é constituído pelos módulos: treinamento, manipulação de arquivos, execução e saída. O módulo de treinamento é responsável, como seu próprio nome indica, pelo processo de aprendizado da rede utilizando-se do algoritmo backpropagation e que é do tipo supervisionado. As funções do módulo de manipulação de arquivo são a de leitura e geração de arquivos, cujos exemplos, gravados em arquivos, são usados no treinamento da RNA, através da leitura destes arquivos.

De posse de um arquivo (imagem exemplo), selecionam-se com o mouse os pixels representativos da microestrutura a ser reconhecida na fase de execução. De cada pixel são extraídas as componentes RGB e atribuído um rótulo ( 9 pseudocores disponíveis) a serem relacionados à microestrutura como legenda (cor associada a cada microestrutura).

O módulo de execução é responsável pelo processo de segmentação das microestruturas, conseqüentemente por sua classificação. Ele somente pode ser usado após o processo de treinamento e se inicia com a abertura de um arquivo (imagem de teste) e finaliza com a apresentação da imagem segmentada e os seus resultados, apresentados na forma área percentual de ocupada por cada microestrutura classificada (região). Isto constitui a saída de dados oriundos do processo de segmentação realizado pela RNA que é visualizado no vídeo ou salva num arquivo texto para posterior manipulação, por exemplo, por uma planilha eletrônica.

\section{METODOLOGIA EXPERIMENTAL}

A parte experimental é realizada, primeiramente, a partir da obtenção dos corpos de prova dos aços ABNT 1020, 1045 e do ferro fundido nodular. A escolha destes materiais para a análise se deve ao fato de estarem presentes em muitas aplicações industriais. As amostras são polidas metalograficamente com pasta de diamante até $1 / 4 \mu$ e atacadas com nital $2 \%$. Em seguida, é feita uma análise no microscópio ótico para verificar se as mesmas estão preparadas para serem submetidas às contagens da fração volumétrica. A partir daí, é usado um disco reticulado de 25 interseções para contar, em diferentes partes do corpo de prova, os 
grãos de ferrita dos aços e os grãos de grafita do ferro fundido nodular, pois, a contagem dos microconstituintes citados diminui o tempo de quantificação dos mesmos, devido à maior quantidade e à fácil visualização no microscópio. Esta etapa é conhecida como metalografia quantitativa convencional. Por fim, capturam-se as imagens das amostras utilizando uma câmera digital para que sejam submetidas ao SVRNA.

A Figura 1 apresenta a tela principal do sistema SVRNA. Nesta figura, a imagem de entrada (esquerda) corresponde a uma amostra de ferro fundido branco eutético, após ataque químico com Nital 2\% com aumento de 430X. Observam-se as imagens de entrada a ser segmentada e a imagem de saída (direita) já segmentada, em que as microestruturas representadas em pseudocores verde, que corresponde à microestrutura de cementita, e amarelo à perlita.

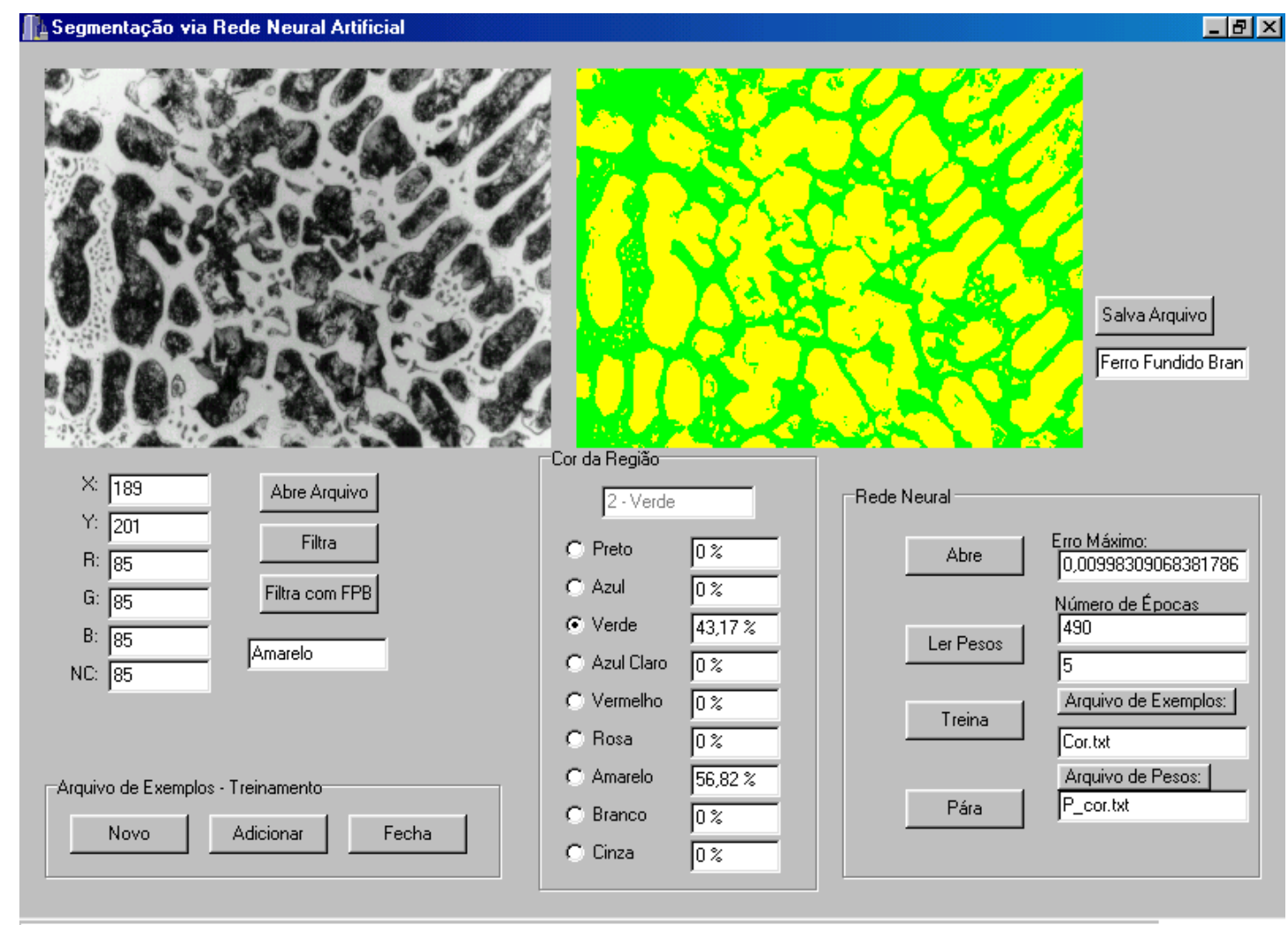

Figura 1: Tela principal do SVRNA para uma imagem de teste.

O software SVRNA fornece, através da interpretação dos pontos marcados nas microestruturas, a quantidade em percentagem de cada constituinte, diminuindo o tempo da Metalografia Quantitativa Convencional.

\section{$5 \quad$ RESULTADOS E DISCUSSÕES}

Os resultados são obtidos para as três amostras que também são submetidas ao método convencional, possibilitando-se uma análise comparativa entre este método e o sistema SVRNA. As figuras desta seção apresentam duas imagens: à esquerda que corresponde à imagem original e à direita que mostra 0 resultado da segmentação empregando o SVRNA.

$\mathrm{Na}$ Figura 2 é mostrada microfotografia de um ferro fundido nodular antes da segmentação empregando o software SVRNA. Na imagem original, a cor preta representa os grãos de grafita e a cor branca a matriz ferrita. A aplicação do SVRNA na imagem original produz uma segmentação, em que a cor azul representa os grãos de grafita e a cor cinza a matriz ferrita. 

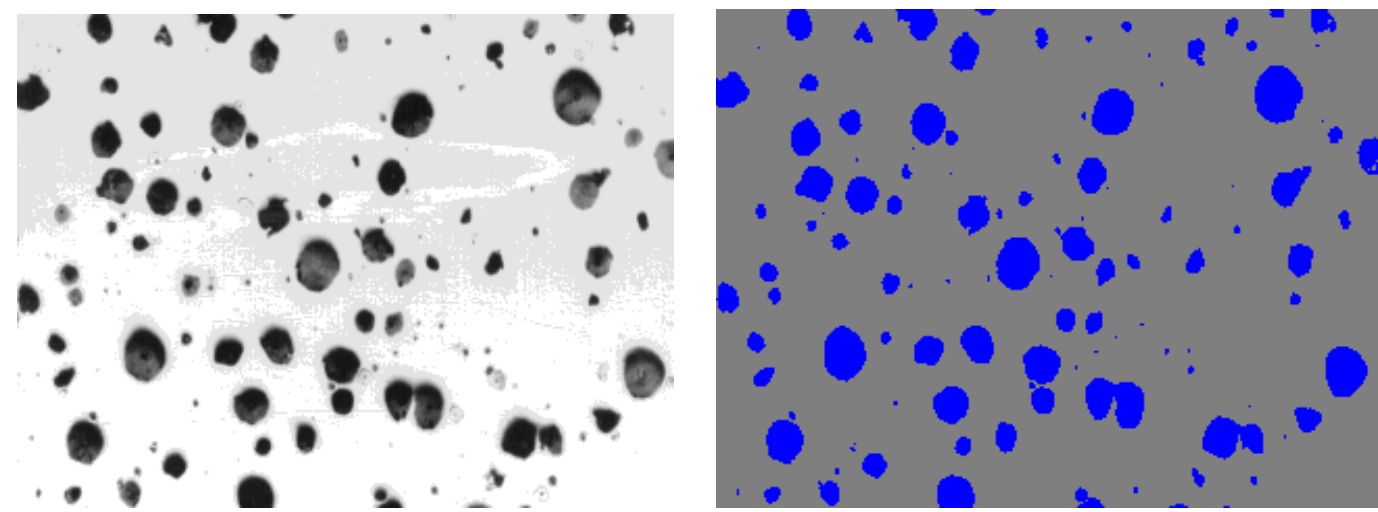

Figura 2: Ferro fundido nodular antes e depois da segmentação, 350X.

Na Figura 3 é mostrada uma microfotografia de um aço ABNT 1020 na sua forma original, em que a cor preta representa os grãos de perlita e a cor branca a matriz ferrita. Após a segmentação utilizando-se o SVRNA, a cor verde representa os grãos de perlita e a cor amarela a matriz ferrítica.
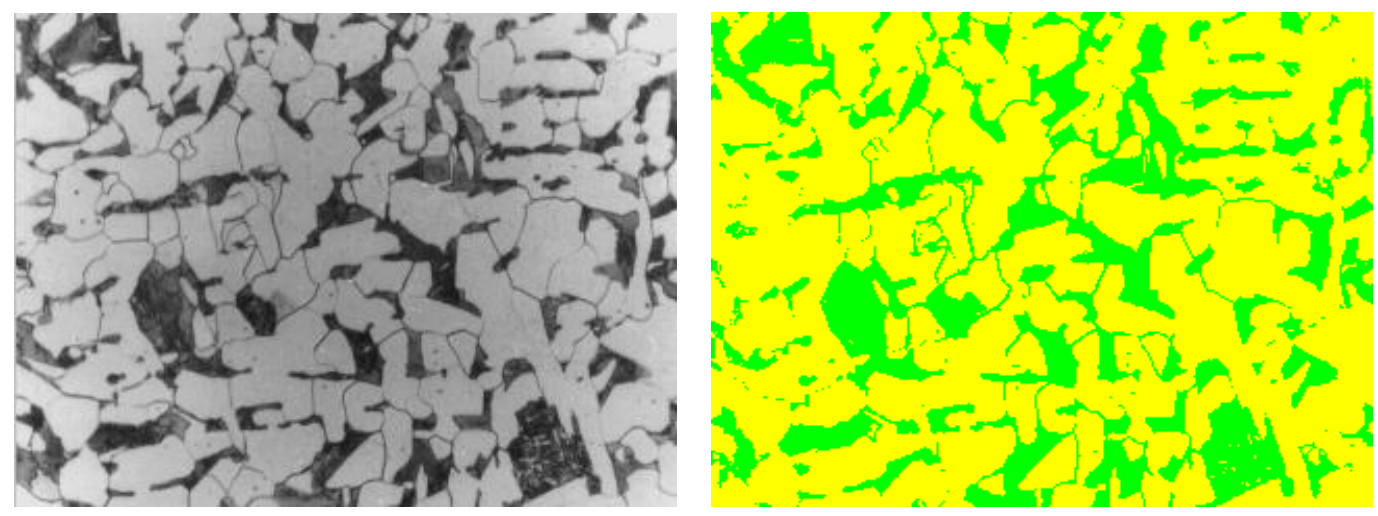

Figura 3: Aço ABNT 1020 antes e depois da segmentação, 346X.

Na Figura 4 é mostrada uma microfotografia de um aço ABNT $1045 \mathrm{Na}$ sua forma original, em que a cor preta representa os grãos de perlita e a cor branca a matriz ferrítica. Após a segmentação utilizando o sistema SVRNA, a cor vermelha representa os grãos de perlita e a cor preta a matriz ferrítica.
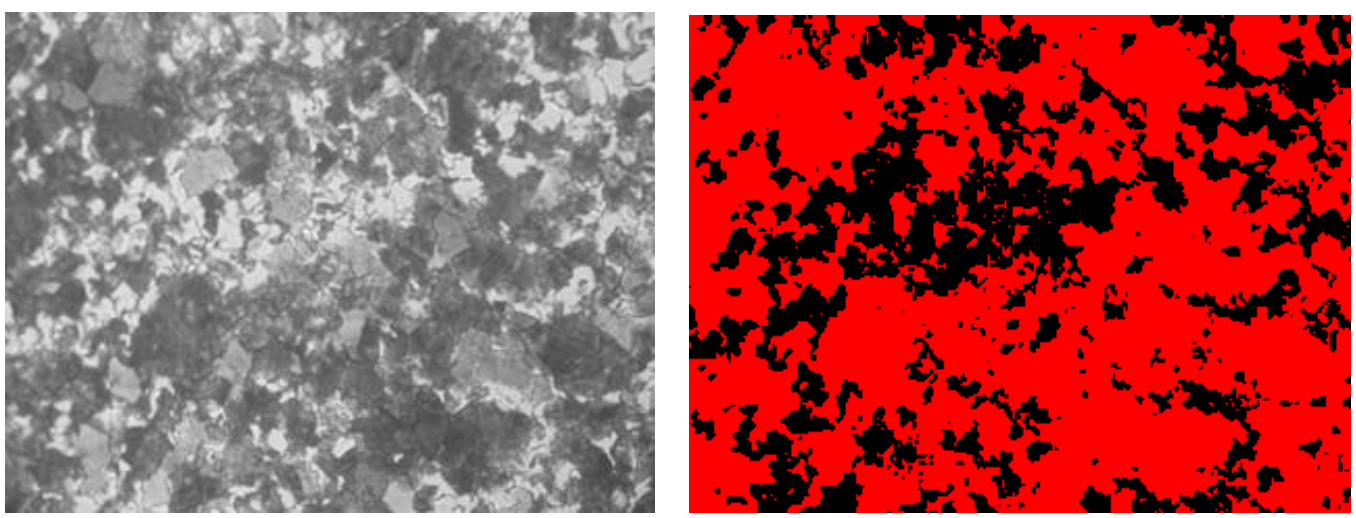

Figura 4: Aço ABNT 1045 antes e depois da segmentação, 351X. 
Observam-se, em todas as figuras apresentadas, que as imagens, antes e após a segmentação, são semelhantes, facilitando, assim, a visualização adequada das microestruturas, demonstrando precisão e confiabilidade nos resultados obtidos pelo emprego do sistema SVRNA.

Na Tabela 3 são apresentados os resultados da aplicação do sistema SVRNA em 10 imagens capturadas de amostras dos aços e ferro fundido e suas respectivas médias.

Tabela 3: Medidas de 10 amostras de cada corpo de prova com a aplicação do SVRNA.

\begin{tabular}{|c|c|c|c|c|c|}
\hline \multicolumn{2}{|c|}{ Aço ABNT 1045 } & \multicolumn{2}{|c|}{ Aço ABNT 1020 } & \multicolumn{2}{c|}{ Ferro Fundido Nodular } \\
\hline Ferrita (\%) & Perlita (\%) & Ferrita (\%) & Perlita (\%) & Ferrita (\%) & Grafita (\%) \\
\hline 38,52 & 61,47 & 73,83 & 26,17 & 85,19 & 14,81 \\
\hline 36,53 & 63,46 & 69,04 & 30,96 & 82,95 & 17,05 \\
\hline 37,2 & 62,79 & 71,5 & 28,5 & 84,82 & 15,18 \\
\hline 40,47 & 59,52 & 67,21 & 32,79 & 85,01 & 14,99 \\
\hline 44,02 & 55,97 & 73,83 & 26,17 & 85,31 & 14,69 \\
\hline 46,38 & 53,61 & 71,71 & 28,29 & 84,75 & 15,25 \\
\hline 39,76 & 60,23 & 67,21 & 32,79 & 85,01 & 14,99 \\
\hline 36,53 & 63,46 & 66,17 & 33,83 & 84,94 & 15,06 \\
\hline 32,26 & 67,73 & 58,29 & 41,71 & 84,75 & 15,25 \\
\hline 41,14 & 58,85 & 59,86 & 40,14 & 84,66 & 15,34 \\
\hline 39,3 & 60,7 & 67,87 & 32,13 & 84,74 & 15,26 \\
\hline
\end{tabular}

Os resultados obtidos para o ferro fundido nodular são bem próximos tanto para a grafita, cujas diferenças máxima e mínima são $2,36 \%$ e $1,71 \%$, respectivamente. Quanto à ferrita, as diferenças máxima e mínima são $2,36 \%$ e $0,12 \%$, respectivamente.

O comportamento de variações de percentuais de microconstituintes para as amostras de aços testados, difere significativamente daquelas diferenças apresentadas pelo ferro fundido nodular. Existe uma diferença máxima de 14,12\% e mínima de 2,36\% de ferrita, e máxima de 14,12\% e mínima de 4,27\% para o microconstituinte perlita do aço 1045. Para o aço 1020 tem-se uma diferença máxima de 15,54\% e mínima de $2,12 \%$ de ferrita, e máxima de $15,54 \%$ e mínima de $1,57 \%$ para o microconstituinte perlita.

Obtêm-se 10 medidas para os microconstituintes, aplicando-se o sistema SVRNA, para cada um dos três tipos de materiais estudados: ferro fundido nodular, aço ABNT 1045 e aço ABNT 1020. Os resultados e suas médias estão mostrados respectivamente nas Figura 5, 6 e 7. 


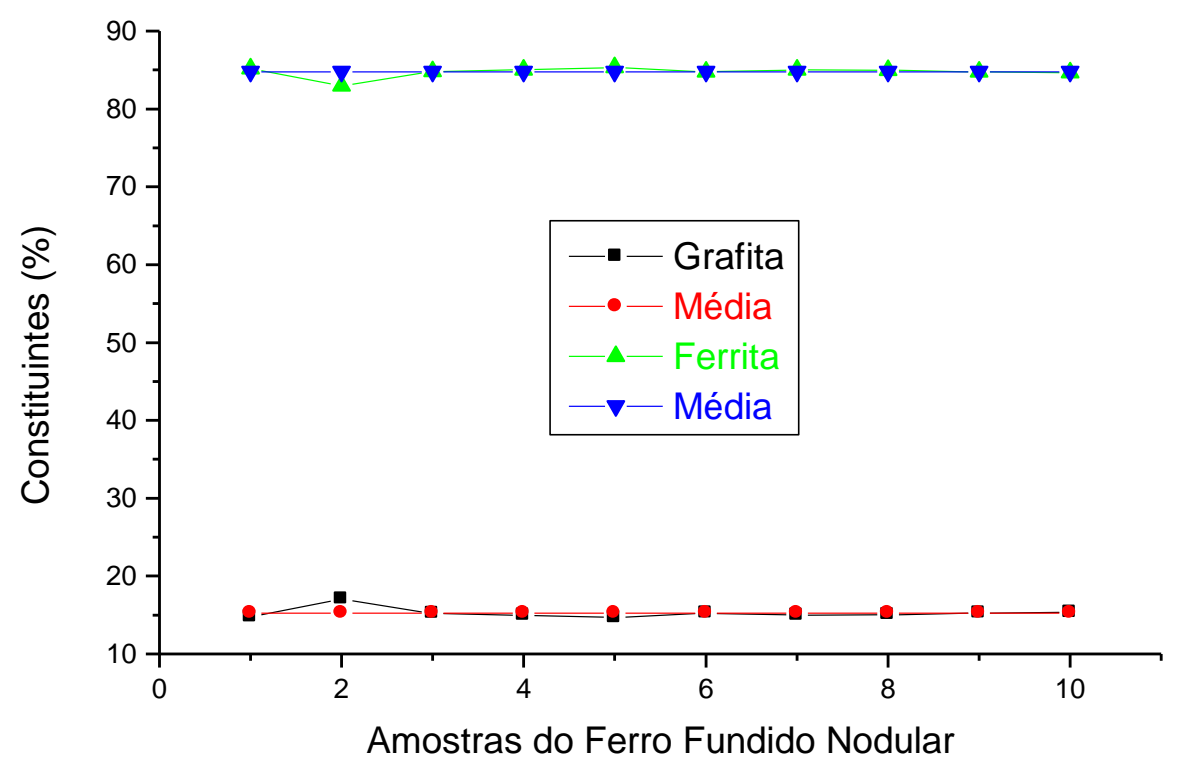

Figura 5: Medidas de ferrita e grafita de 10 amostras e suas médias para o ferro fundido nodular.

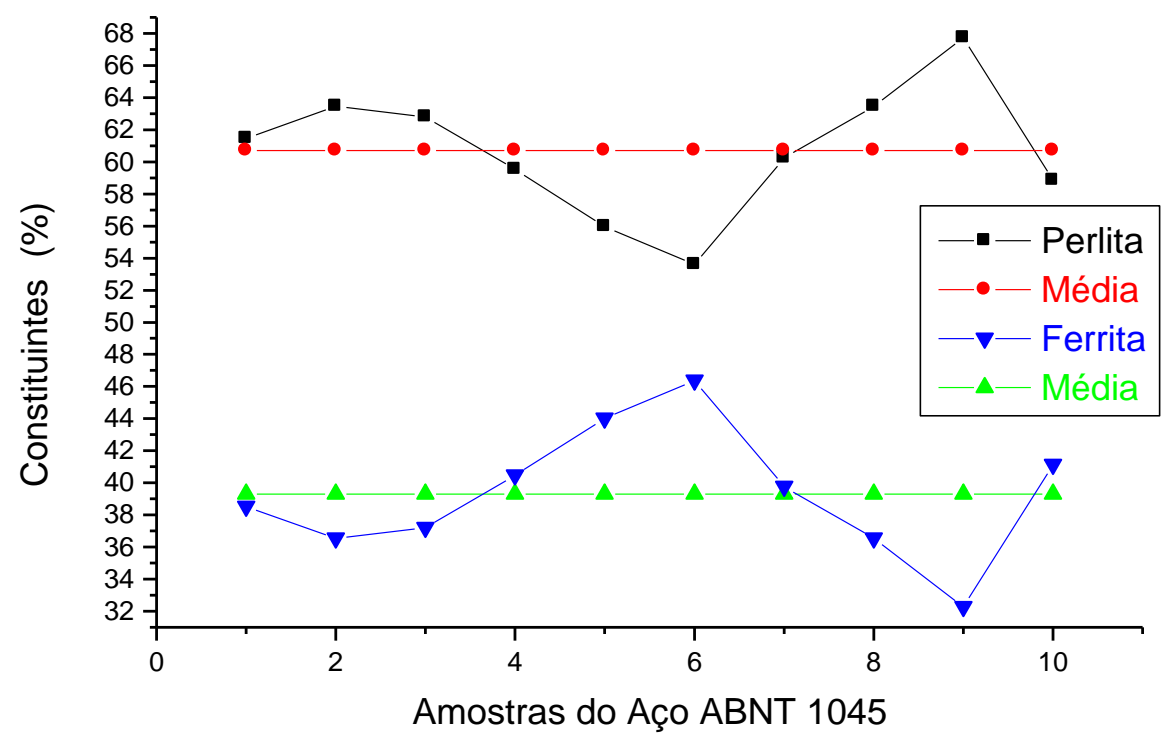

Figura 6: Medidas de ferrita e perlita de 10 amostras e a suas médias para o aço ABNT 1045. 


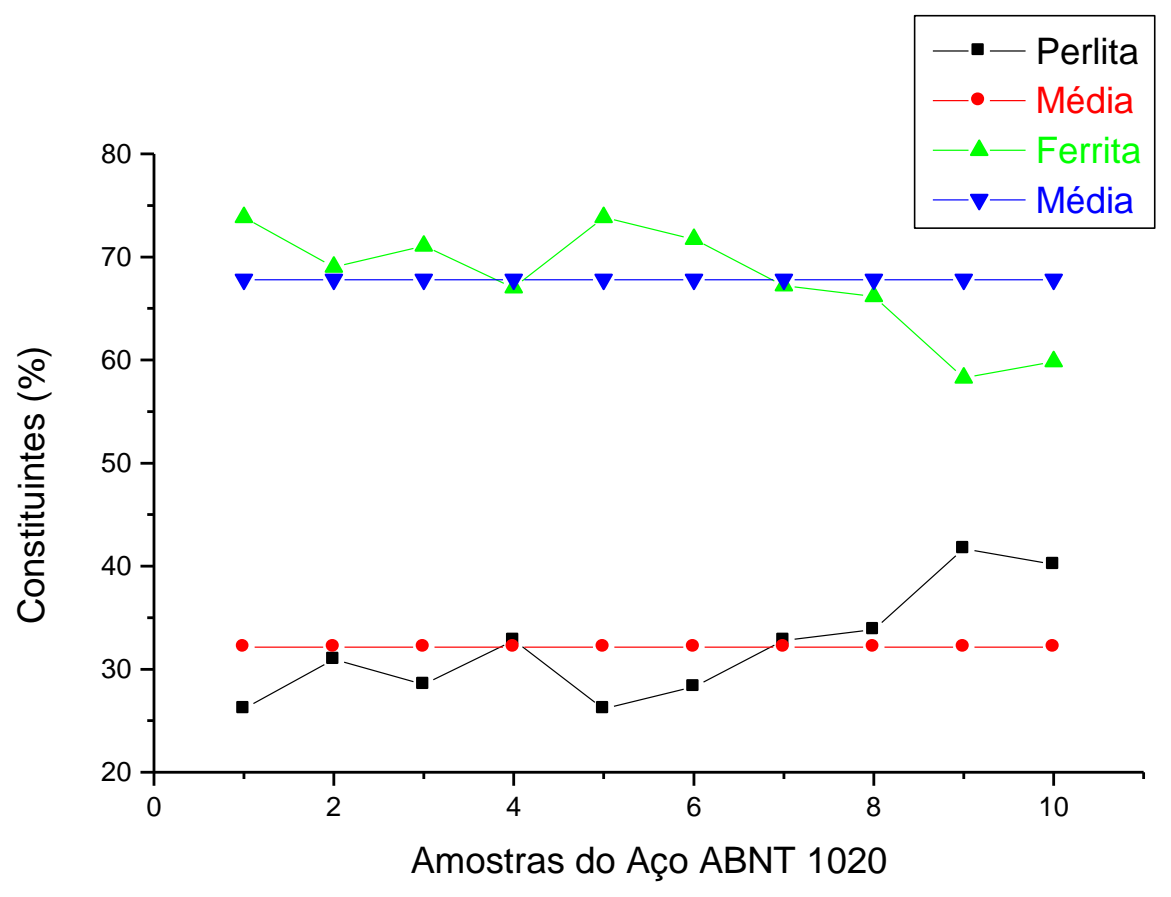

Figura 7: Medidas de ferrita e perlita de 10 mostras e suas médias para o aço ABNT 1020.

A partir dos gráficos contidos na Figura 5, observa-se uma reduzida dispersão dos resultados obtidos em torno da média para os dois microconstituintes. Isto é devido à homogeneidade do ferro fundido nodular.

Observando-se os gráficos mostrados na Figura 6, evidencia-se uma dispersão dos resultados obtidos para o aço ABNT 1045, em relação às médias e numa intensidade maior do que a do aço ABNT 1020, mostrado na Figura 7. Desta forma, este aço apresenta-se mais heterogêneo que o ferro fundido nodular e mais homogêneo que o aço ABNT 1045.

Outro fator que pode ter ocasionado a dispersão dos resultados obtidos das amostras de ferro fundido, aço 1045 e aço 1020 em relação às médias, além da forma de distribuição (homogeneidade e heterogeneidade) das microestruturas, é o fato de que, a segmentação das imagens está associada apenas aos níveis de cinza.

Uma análise comparativa entre as medidas realizadas pelo modelo convencional e pelo SVRNA é mostrada na Tabela 4 com as médias de 10 imagens.

Tabela 4: Médias dos microconstituintes com a aplicação do SVRNA e com o modelo convencional aplicados às amostras testadas.

\begin{tabular}{|l|c|c|c|c|c|c|}
\hline \multirow{2}{*}{ MÉTODOS } & \multicolumn{2}{|c|}{ Aço ABNT 1045 } & \multicolumn{2}{c|}{ Aço ABNT 1020 } & \multicolumn{2}{c|}{ Ferro fundido nodular } \\
\cline { 2 - 7 } & Perlita (\%) & Ferrita (\%) & Perlita (\%) & Ferrita (\%) & Ferrita (\%) & Grafita (\%) \\
\hline SVRNA & 60,7 & 39,3 & 32,21 & 67,79 & 84,74 & 15,26 \\
\hline CONVENCIONAL & 53,41 & 46,59 & 30,62 & 69,38 & 75,87 & 24,13 \\
\hline
\end{tabular}

Nota-se que existem diferenças entre o método convencional e o SVRNA, sendo estas de 7,29 \% para o aço 1045, 1,59\% para o aço 1020 e 8,87\% para o ferro fundido nodular. Estas diferenças são oriundas dos seguintes fatores: má preparação das amostras durante a metalografia, processo cansativo da quantificação de microestruturas através da metalografia convencional; não abrangência da superfície total das amostras durante a contagem dos microconstituintes.

Embora o SVRNA tenha demonstrado sua eficiência, sua aplicação pode ficar comprometida em microestruturas mais complexas quanto a sua identificação visual como, por exemplo, em micrografias de estruturas eutéticas. Por apresentar níveis de cinza semelhantes, a perlita e os glóbulos de perlita de um ferro 
fundido branco eutético são quantificados como uma única microestrutura, podendo ser visto nas Figuras 8 (antes) e 9 (após a segmentação) que mostra a dificuldade na quantificação do constituinte ledeburita II. Após a segmentação, Figura 9, o software SVRNA não quantifica a ledeburita em si, mas sim a matriz de cementita e os glóbulos de perlita.

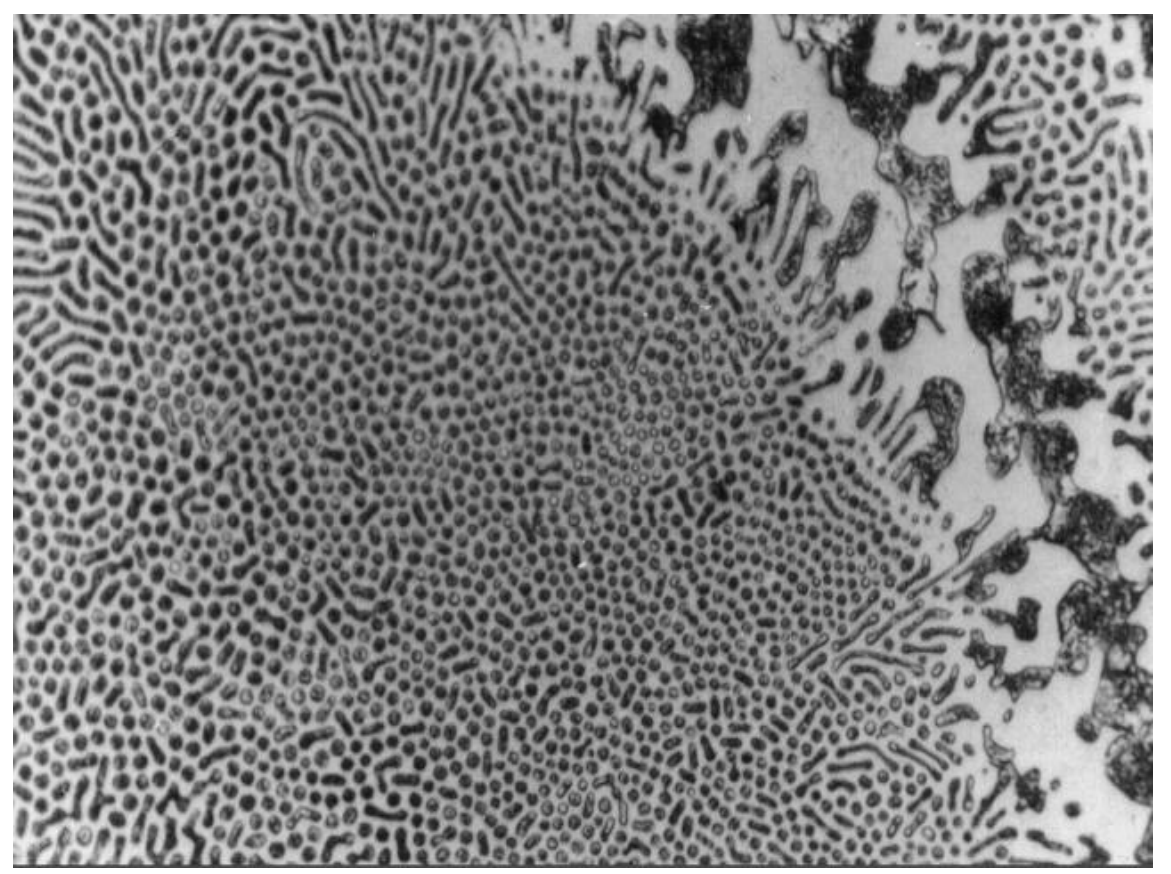

Figura 8: Ferro fundido branco eutético. Ledeburita II. Antes da segmentação, 809X.

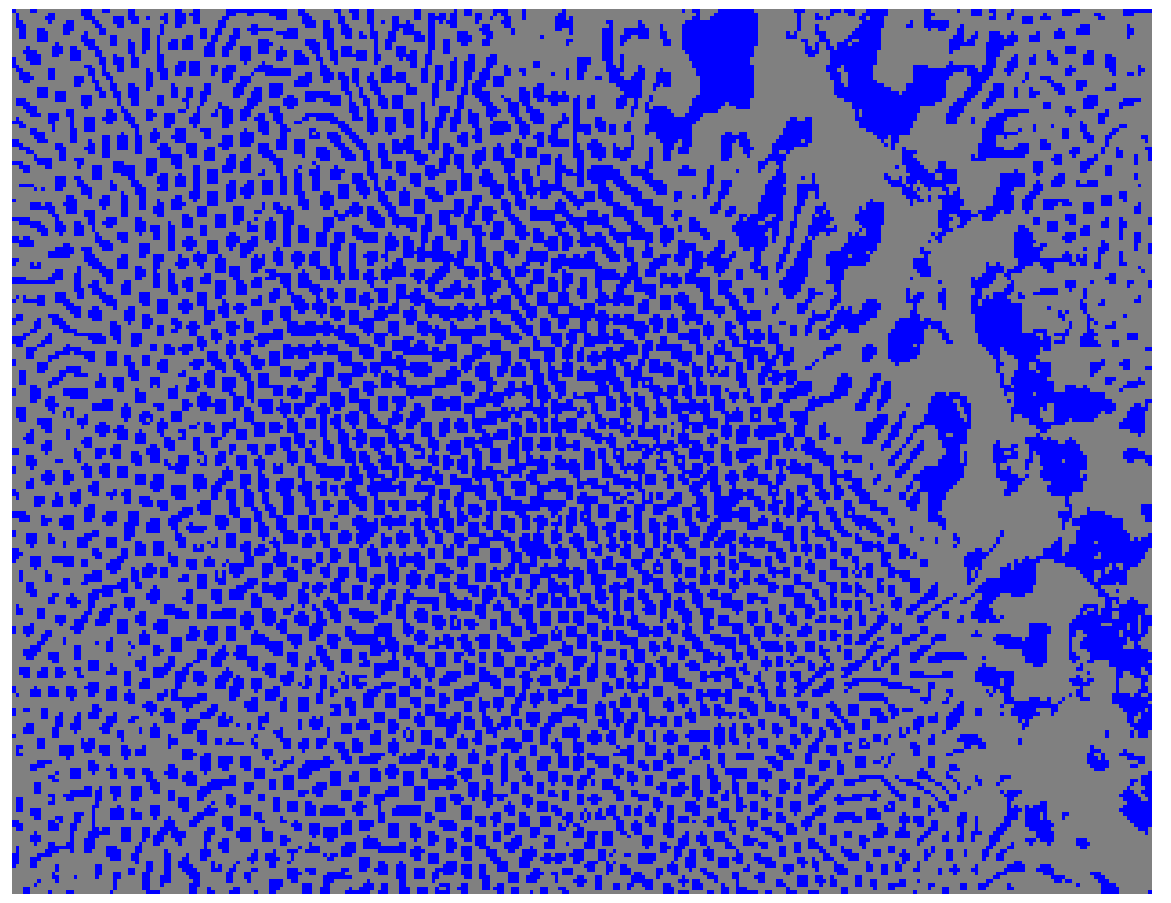

Figura 9: Ferro fundido branco eutético. Ledeburita II. Após a segmentação, 809X.

Para solucionar este problema de segmentação estão sendo realizados estudos utilizando outras técnicas de segmentação como, por exemplo, morfologia matemática. 


\section{CONCLUSÕES}

Este trabalho apresenta uma análise comparativa entre o método convencional e o método que emprega Redes Neurais Artificiais para a quantificação de microestruturas, em amostras de ferro fundido nodular e dos aços ABNT 1020 e 1045. Isto constitui a principal contribuição deste trabalho.

Utilizando-se de vários experimentos metalográficos, em diferentes amostras de metais, conclui-se que o software SVRNA pode ser utilizado em aplicações na área das Ciências dos Materiais para a determinação da fração volumétrica de microestruturas. Este sistema apresenta como principal vantagem a redução considerável no tempo para a contagem dos microconstituintes.

Vantagens adicionais podem ser observadas no SVRNA, como a facilidade do treinamento por parte do operador e a robustez da rede em relação a ruídos causados, principalmente, por distorções na parte óptica ou irregularidades na iluminação durante aquisição das imagens das microestruturas. Como consequiência de suas vantagens, o SVRNA garante resultados satisfatórios em menor tempo.

A partir da análise dos resultados, nota-se que o software SVRNA apresenta-se eficaz para o grau de significância admitido, com isto, este programa está apto para ser utilizado intensivamente.

Porém, durante o desenvolvimento deste trabalho, constata-se que o SVRNA não é tão eficiente para ser aplicado em constituintes eutéticos, como a ledeburita, pois, reconhece e quantifica constituintes homogêneos e heterogêneos com pequenos aumentos, onde o mesmo se apresenta como se fosse uma única fase como, por exemplo, a perlita que aparece com uma região escura. Entretanto, estudos preliminares buscam uma melhor forma de solucionar este problema.

\section{BIBLIOGRAFIA}

[1] SOUZA, F.P.C., SUSIN, A., "SIAV - Um Sistema de Identificação Automática de Veículos", In: Congresso Brasileiro de Automática, CBA2000, Florianópolis, pp. 1377-1380, 2000.

[2] ACHA, B., SERRANO, C., "Image Classification Based on Color and Texture Analysis", IWISPA 2000 PROGRAM, 2000.

[3] VAN DER HEIDJEN, F., Image based Measurement Systems Object Recognition and Parameter Estimation, Inglaterra, John Wiley \& Sons Ltd, 1994.

[4] PLAUT, D., NOWLAN, S., HINTON, G.E., "Experiments on Learning by Back Propagation", In: Technical Report CMU-CS-86-126, Computer Science Department Carnegie Mellon University, 1986.

[5] BHADESHIA, H.K.D.H., "Neural Networks in Materials Science”, ISIJ International, v. 39, n. 10, pp. 966-979, 1999.

[6] MIAOQUAN, L., LIU, X., XIONG, A., LI, X., "Microstructural Evolution and Modelling of the hot Compression of a TC6 Titanium Alloy”, Materials Characterization, v. 49, pp. 203-209, 2003.

[7] MIAOQUAN, L., LIU, X, XIONG, A., LI, X. "An adaptive Prediction Model of Grain Size for the Forging of Ti-6Al-4V Alloy Based on the Fuzzy Neural Networks", Journal of Materials Processing Technology, v. 123, n. 3, pp. 377-381, 2002.

[8] LI, X., MIAOQUAN, L., "Microstructure Evolution Model based on Deformation Mechanism of Titanium Alloy in hot Formin", Transactions of Nonferrous Metals Society of China, v. 15, n. 4, pp. 749-753, 2005.

[9] PADILHA, A.F., Materiais de Engenharia: Microestrutura e Propriedades, São Paulo, Hemus Editora Ltda, 1997.

[10] UNDERWOOD, E., Quantitative Stereology, Addison Wesley Publishing, Londres, 1970.

[11] SEABRA, A.V., Correlação das Propriedades Mecânicas dos Aços com a Microestrutura, Lisboa, Memória lnec, n. 522, 1979. 
[12] DAMAZIO, D.O., SEIXAS, J.M., SOARES, A.C., "Efeito da Estimação do Ruído Ambiente na Classificação com Redes Neurais do Ruído Irradiado por Navios”, In: XIII Congresso Brasileiro de Automática, Florianópolis, 2000.

[13] GUYON, I., "Neural Networks and Applications Tutorial”, Physics Reports (Review Section of Physics Letters), North-Holland, n. 3-5, pp. 215-259, 1991.

[14] HAYKIN, S., Neural Networks - A Comprehensive Foundation, Macmillian College Publishing Company Inc, EUA, 1994.

[15] PETERSEN, M.E., RIDDER, D. e HANDELS, D., "Image Processing with Neural Networks: A Review”, The Journal of the Pattern Recognition Society, v. 35, pp. 2279-2301, 2002.

[16] MOERLAND, P., FIESLER, E., "Neural Network Adaptations to Hardware Implementations", Handbook of Neural Computation, Institute of Physics Publishing and Oxford University Publishing, v. E1.2, pp. 1-13, Nova Iorque, 1997.

[17] WOLF, D.F., FARIA, G., ROMERO, R.A.F., MARQUES, E., et al., "A Pipeline Hardware Implementation for an Artificial Neural Network", In: Congresso da Sociedade Brasileira de Computacão - SBC, Encontro Nacional de Inteligência Artificial - ENIA, Fortaleza, v. 1, pp. 15281536, 2001.

[18] ALBUQUERQUE, V.H.C., “Análise de Microfotografias e Quantificação de Microconstituintes através de um Sistema Baseado em Redes Neurais Artificiais", Monografia, Centro Federal de Educação Tecnológica do Ceará, 2005. 